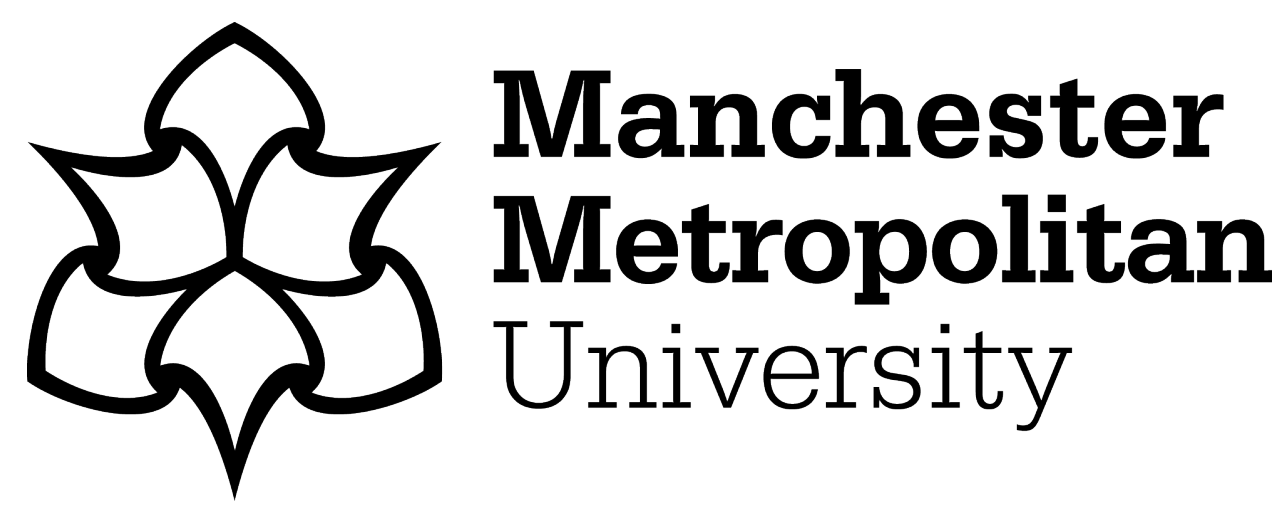

Tyler, David (2001) Cognitive mapping: a tool to support strategic management. Journal of Fashion Marketing and Management: An International Journal, 5 (4). pp. 353-357. ISSN 1361-2026

Downloaded from: https://e-space.mmu.ac.uk/622493/

Version: Accepted Version

Publisher: Emerald

DOI: https://doi.org/10.1108/eum0000000007296

Please cite the published version 


\title{
Cognitive mapping: A tool to support strategic management
}

\begin{abstract}
This paper considers the use of cognitive mapping to support strategy development involving managers of small businesses.
\end{abstract}

Keywords:

cognitive mapping, investment decisions, strategic management, strategy

\section{Introduction}

Management studies of decision making, organisational culture and the process of change all require tools for data collection and frameworks for analysis and understanding. Working with companies to introduce operational teams, it has become apparent to the author that the most radical changes needed are attitudinal: affecting managers, supervisors and operators. This was found to be the case in projects that went across the industry: clothing assembly, knitwear assembly, knitted fabric manufacture, spinning and carding. Whilst various operational techniques were employed to facilitate the needed changes, the ability to capture and analyse workplace culture was found to be consistently problematic. An approach involving Lickert Scales offered potential, but this was by no means straightforward because of the way respondents placed different and sometimes inconsistent interpretations on the statements presented to them.
These experiences have stimulated a search for reliable tools to analyse management culture, and the most fruitful of these has been the technique of cognitive mapping. The tool was first used to study the development of corporate strategy by senior managers (Eden 1988) and it is being applied in numerous other areas (Eden and Ackermann 1998). The author's experience with the technique includes strategic thinking by the managers of small businesses, the contrasting cultural perspectives of project leaders and helping researchers to gain a grasp of their research domains and the appropriate methodologies they should be using.

\section{Cognitive mapping principles}

Cognitive mapping takes place during an interview between the analyst and the subject. Typically, an initial session will last about an hour and the discussion will be wide-ranging.

Concepts about the different aspects of 
the business strategy are elicited from the subject (the proprietor or senior manager). These concepts may articulate company goals, elaborate on issues affecting the company, or they may relate to the activities that are being managed on a day to day basis. The concepts are expressed as short phrases of text. Concepts are retained in the words of the subject wherever possible, because it is important that the manager feels a sense of ownership over the emerging map. Due to the nature of the tool, it is not necessary to structure the interview: subjects are led only in the sense that linkages between concepts are probed by the analyst.

Concepts are linked together to express the relationships that are perceived by the subject. Causal links are the dominant type of link, conveying 'Concept A may lead to Concept B'. These may be negative, 'Concept A inhibits reaching Concept B'. Other types of linkage are possible, but entirely dependent on the subject's perceptions of the way the business functions. Linkages capture the relationships that exist in the mind of the subject, making visible a cognitive map of management thinking.

In a mapping session, concepts are recorded on paper, as they are identified. Thus, the subject witnesses the map developing as the interview proceeds. The starting point is usually in terms of a major aim (or aims) of company activity. Links are then sought in terms of how the aim (or aims) is achieved, and the consequences for the company if the aims are achieved.

The cognitive mapping work reported here used computer software known as Decision Explorer. If desired, the computer map produced by the software can exactly replicate the paper version. However, in practice, concepts are generally repositioned (and re-numbered), to improve the presentation, primarily to make linkages clearer. This software is well supported by a website (Banxia Software 2001), where visitors can download demonstration software, work through tutorials and access training material and other resources.

\section{Using cognitive mapping in practice: Star Enterprise}

Star Enterprise is a small company employing about 20 people. The Company is in the household textile sector and concentrates on small batch production. Although profitability has been acceptable in the past, Star Enterprise is currently experiencing price competition and is concerned about its future trading prospects.

Initial work with cognitive mapping addressed present goals and practices within the Company. For example, questions about factors affecting success generally met with replies about production volume. Following this up, production volume was perceived as the way to make more profit. In response to the question, 'What are you seeking to do to make the company successful?', the subject replied: 'I'm trying to increase the volumes of production'. 'Why do you want to increase volumes?' received the reply: 'To make more money'. The logic behind these responses is that production volume brings in a sales margin, and if volumes can be increased with existing capacity, the profitability is increased.

By continuing to probe the dominant concepts in the thinking of the manager, Figure 1 emerged as the cognitive map of the current strategy operating in Star Enterprise.

There was another route to making money that was recognised by the manager: increasing margins on products sold. Much effort had been given to increasing margins by purchasing materials more competitively, but the opportunities for doing this were largely exhausted and not helped by the policy of small batch production within Star Enterprise. Increasing prices was not an option because of price competition.

To increase production volumes, the only strategy identified was to improve production efficiencies. This implies the more efficient use of existing machinery or investment in new machinery. Higher production efficiencies would also have the 


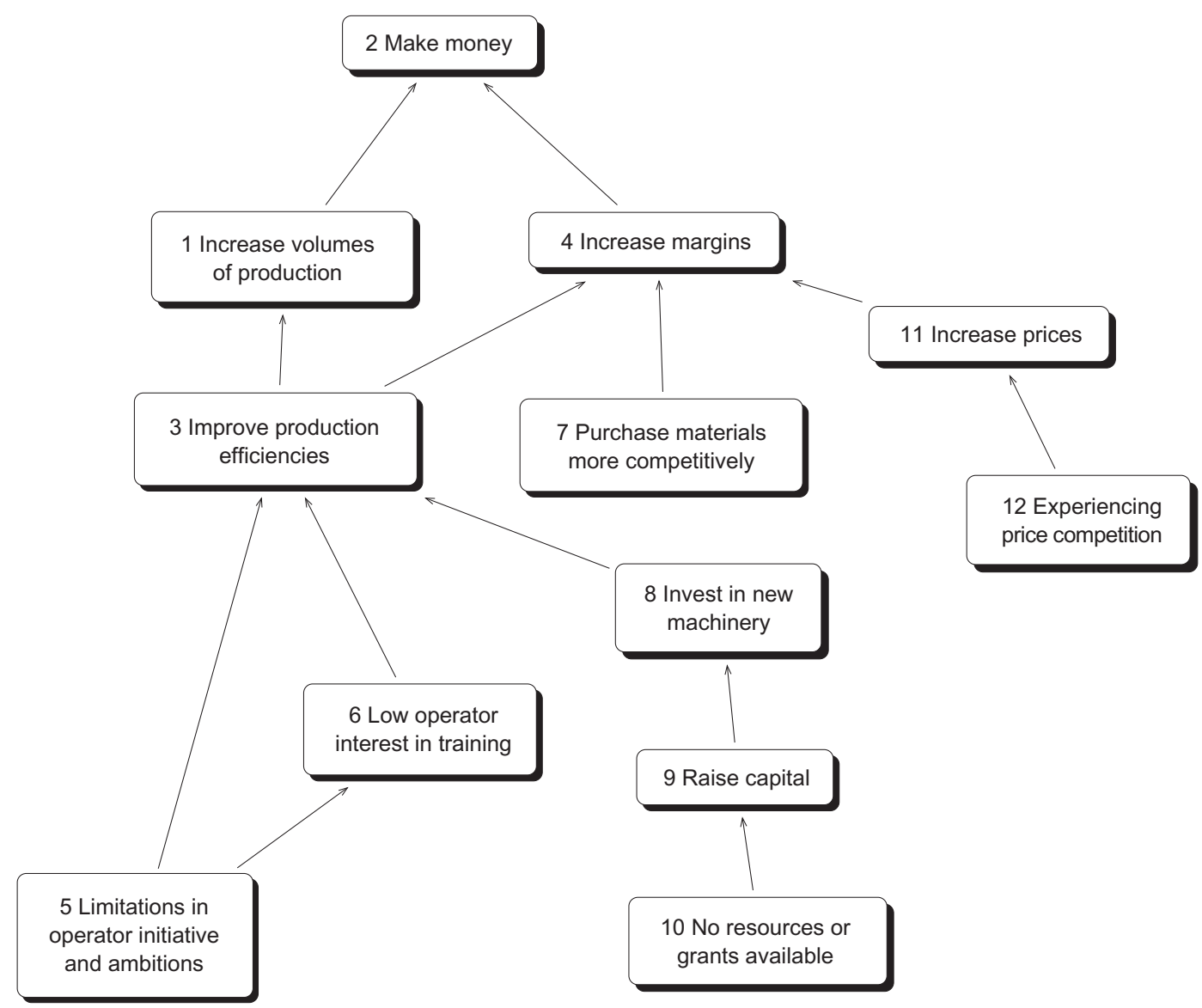

Fig. 1 Cognitive map of current management strategy

effect of increasing margins. However, the workforce was not perceived by the manager as amenable to change. Initiative levels were not high and operators were not considered to be ambitious. Interest in training was low. Thus, concepts (5) and (6) have negative causal links to (3).

Investment in new machinery was perceived as the primary way forward for the company. The only future considered viable was one involving capital investment. However, raising the capital was a major problem. The company had no financial resources, and capital grants were not available.

The result was an impasse. The manager considered that the failure of government to provide assistance with capital projects was threatening the future of the business.

The cognitive map was then developed to consider other alternatives open to the business. This step involved some prompting, but the emerging concepts were elicited from the manager, not introduced by the interviewer. The result is in Figure 2.

The first alternative discussed was exports (13) - primarily because the Company has considered this in the past, but has not progressed this option. They realised that developing export markets is very demanding, not the least involving searching out new customers (18). However, two major hurdles within the company were perceived: the lack of access to vacuum packing of their product (14) and the need for enhancements to storage areas that were already fully used (15). The difficulty in raising the capital (16) was the same as for machinery investment (10).

The other avenue explored was branded fashion products (17). The company had a little experience of this, having two brands 


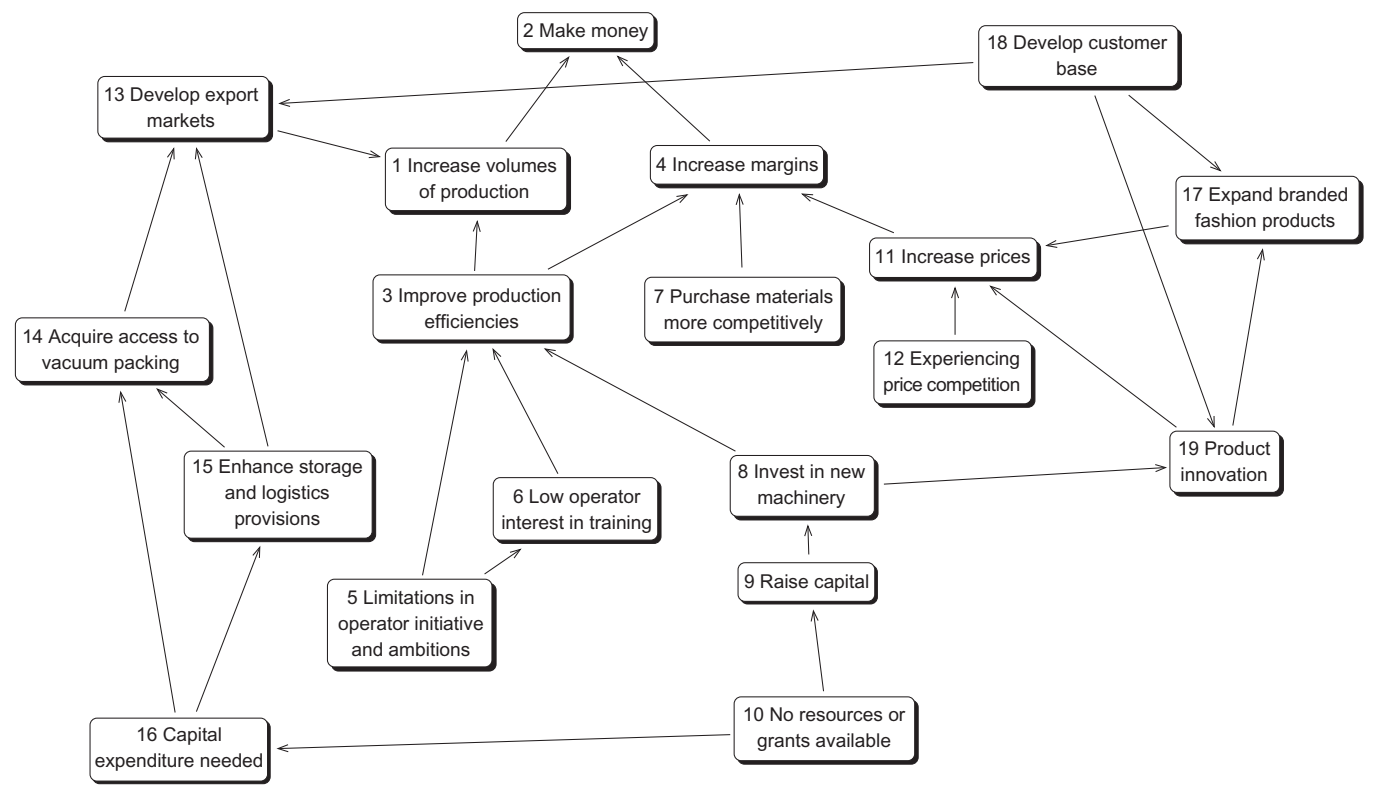

Fig. 2 Cognitive map documenting the enlarged strategy

of their own running alongside other customer brands. The existing brands were not differentiated in any way from other brands and brand management did not feature in the interview. However, there was a perception that if this side of the business were to be expanded, it would require work to develop the customer base (18) and innovation (19). The manager recognised that there were rewards (11). The block on innovation was that this was associated again with machinery investment (8) which was not happening (10).

After these two stages of analysis, the issues and problems for strategic management of the company were captured in a highly visual way. The response from the manager was one of appreciation. His lifestyle was very busy and the opportunity to reflect on strategy was almost a luxury. He found it a useful experience to go through, as many of the linkages in the cognitive map were only dimly perceived before the interview.

\section{Conclusion}

Cognitive mapping is proving a valuable tool in assisting managers to think through issues of strategy. In the case of Star
Enterprise, as with many others, managers tend to find mental blockages that inhibit strategic change. The manager concerned in this case study responded positively to the way he was able to appreciate more fully, how a decision affecting one part of the business was likely to impact on other parts. The next step for this manager is to develop the strategy by further mapping sessions, exploring a variety of 'what if?' questions.

Many managers appear to think that access to capital resources is the primary need of their businesses. This can lead to a blame culture, where managers feel trapped within the existing structure of the business. This story is illustrated by Star Enterprise and is not unusual. Many companies, when asked what support agencies can do for them, say that they are looking primarily for capital grant support. The reality of the situation is that government provides 'soft' support to industry (business advice, market information, training support and so on.) The mismatch between the perceived needs of companies and the available support is contributing to the feeling that industry is not getting a fair deal.

These findings are of great significance for business advisors and support agencies. The challenge is to help companies escape the 
straitjacket of 'No capital resources' and to help managers find realistic ways of developing their businesses. To this end, cognitive maps are a good foundation on which to build.

\section{Acknowledgements}

This work was part-funded by the European Regional Development Fund and co-ordinated by North West Regional
Technology Web Limited, project reference: NWTW/AP/01/26/007.

\section{References}

Banxia Software (2001) http:/ / www.banxia.com/ demain.html.

Eden, C. (1988) 'Cognitive mapping', European Journal of Operational Research, Vol. 36, pp. 1-13.

Eden, C. and Ackermann, F. (1998) 'Making Strategy, The Journey of Strategic Management'. Sage Publications, London. 